\title{
BARRED OWLS AT MADGE LAKE, SASKATCHEWAN
}

\author{
by Robert J. Long, Saskatchewan Museum of Natural History, Regina
}

Records for the Barred Owl in Saskatchewan are few. The first specimen was taken in 1959 (Houston, Blue Jay, $17: 94)$ and a nest was reported in 1961 (Houston, Blue Jay, 19:114). During this period, and up to the present time, there have been several reports of brief sightings.

Between July 21 and August 29, 1970, I made several observations on this species at Madge Lake, Saskatchewan. Barred Owl calls were heard frequently, and on several occasions I was struck by the prevalence of mid-day calling. I suspect that this was the result of weather conditions on those particular days. On several occasions I answered owl calls, but was unable to draw the bird closer. As a relative newcomer to the province, I was unaware that Barred Owls are rare here, so I made little attempt to follow up these auditory observations.

At 1:30 a.m. on July 29, I was awakened by loud calling near my quarters. I moved outside and set up a tape recorder with a parobolic reflecting microphone and recorded several calls. As I recorded, a second owl approached, and there resulted a noisy interaction - all of which is now on tape. Of course, I could not see the birds, but it appeared as though this was an interaction between territorial individuals.

On August 8, at 11:00 a.m., I came across an adult Barred Owl sitting in the middle of a secondary road. Thinking it to be injured, I stopped and approached the bird, but it flew off into the trees. I followed hoping to get some pictures, and found it sitting 25 feet up in a spruce. For 20 minutes I worked with the owl, moving around below it, and making several trips back to the car for different equipment. Throughout all of this, the owl merely watched as I moved, and appeared to lose interest if I stood still. It changed

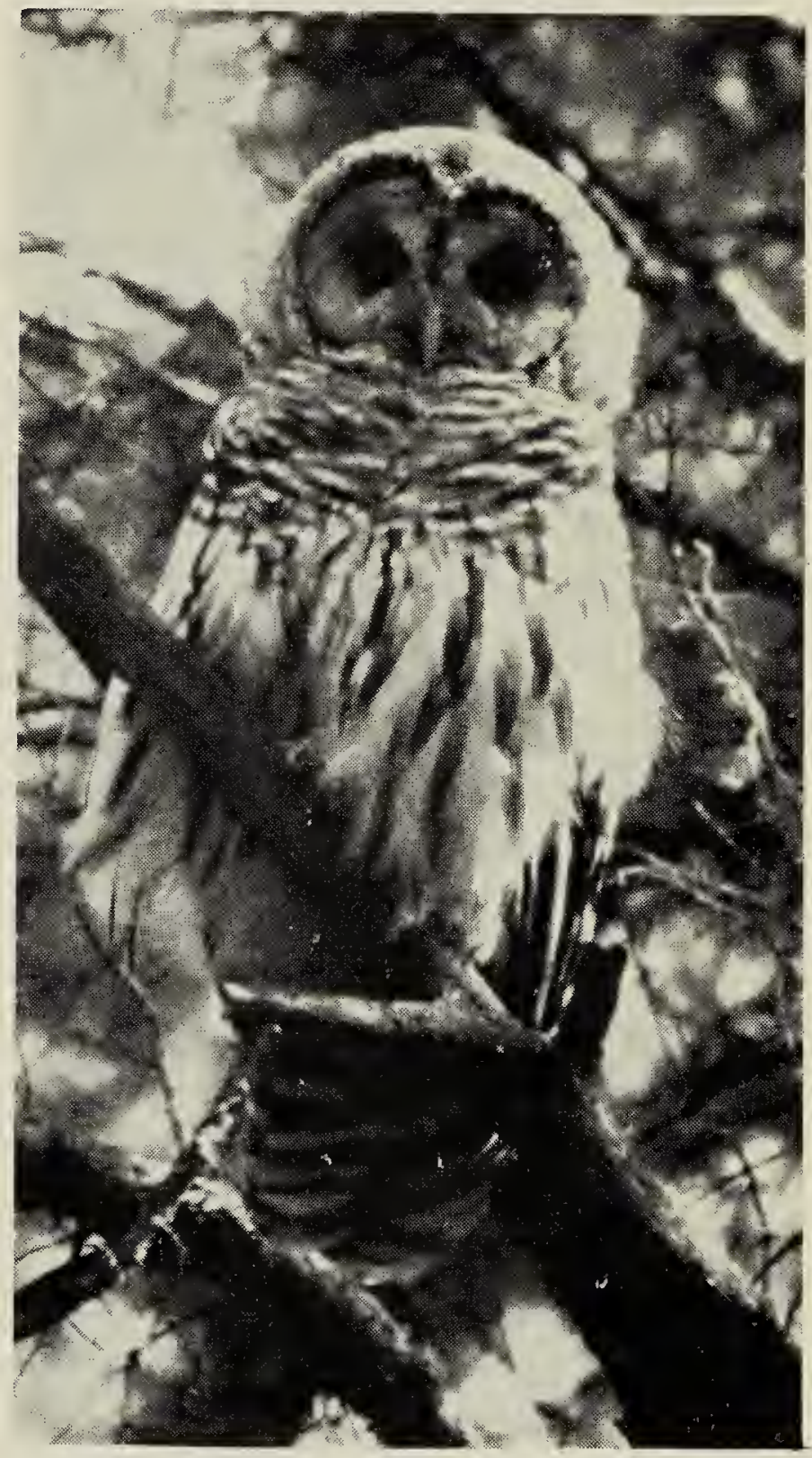

Photo by R. J. Long

Barred Owl at

Madge Lake, 1970.

position twice, flying about 50 feet each time. I left the owl sitting as calmly as I had found it.

Barred Owls are common in my home province of Ontario, yet I have never heard their calls as frequently as at Madge Lake. It would appear that there was a high density of these birds in the vicinity. This may have been a temporary local concentration, or it may indicate at trend towards increasing abundance of Barred Owls in Saskatchewan. 